\title{
Antiviral Treatment Strategies in COVID-19
}

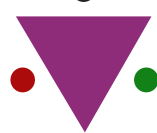

IJCRR

Section: Healthcare Sci. Journal Impact Factor: $6.1(2018)$ ICV: 90.90 (2018)

\section{Jai Rexlin P. E. ${ }^{1}$, Anitha Roy ${ }^{2}$}

'Saveetha Dental College and Hospitals, Saveetha Institute of Medical and Technical Sciences, Saveetha University, Chennai 77, Tamil Nadu, India; ${ }^{2}$ Department of Pharmacology, Saveetha Dental College and Hospitals, Saveetha Institute of Medical and Technical Sciences, Saveetha University, Chennai 77, Tamil Nadu, India.

\section{ABSTRACT}

Background: Early in December 2019, a novel coronavirus, named SARS-CoV-2, caused an outbreak of respiratory disease named COVID-19. The COVID-19 disease has led to severe pneumonia, multiorgan failure, and death.

Methods: A detailed literature survey was performed using various databases.

Results: Lopinavir/Ritonavir is an orally administrable drug, and after its administration, the viral load is being tested. On the other end, remdesivir even at a very low micromolar concentration blocked the viral infection. Ribavirin combination with Lopinavir/ Ritonavir was intravenously infused for not more than 10 days. The presence or absence of viral load was determined to be the endpoint. Gastrointestinal adverse events were more common in the lopinavir-ritonavir administered patients. Lopinavir-ritonavir treatment was stopped early in patients because of adverse events. Hypertransaminasemia and acute kidney injury were also the most frequent severe adverse events observed. Remdesivir benefited patients with SARS-CoV-2 pneumonia hospitalized outside ICU where the clinical outcome was better and adverse events are less frequently observed. Ribavirin combination with Lopinavir/ Ritonavir was intravenously infused for not more than 10 days and was found to be less effective.

Conclusion: The antiviral drugs involved in the treatment of COVID 19 are Lopinavir/Ritonavir, Remdesivir, and Ribavirin. Among which Remdesivir was found to be more effective against COVID 19 with 30\% speedy recovery. However, prevention is always better than cure, the prevention methods involve Hand sanitization, gloves, masks, protective suits, social distancing, and self-isolation.

Key Words: COVID-19, Anti-viral, Lopinavir/ Ritonavir, Remdesivir, Ribavirin, Favipiravir

\section{INTRODUCTION}

Early in December 2019, a novel coronavirus, named SARS$\mathrm{CoV}-2$, caused an outbreak of respiratory disease named COVID-19. Coronavirus is an RNA virus and possesses a crown-like appearance under an electron magnifying instrument because of the presence of spike glycoproteins on the envelope. The subfamily Orthocoronavirinae of the Coronaviridae family is classified into four genera of CoVs: Alphacoronavirus, Betacoronavirus, Deltacoronavirus, and Gamma Coronavirus. Moreover, the Betacoronavirus isolates into five sub-genera or lineages. The genomic portrayal has demonstrated that most likely bats and rodents are the quality wellsprings of alpha coronaviruses and beta coronaviruses. Despite what might be expected, avian species appear to speak to the quality wellsprings of Deltacoronavirus and Gamma Coronavirus. The full spectrum ranges from mild, self-limiting respiratory tract illness to severe progressive pneumonia, multiorgan dysfunction, and death. So far, there are no particular therapeutic agents for coronavirus disease ${ }^{1-4}$. After the rise of Severe Acute Respiratory Syndrome (SARS), screening of affirmed drugs recognized lopinavir, in vitro was found to have inhibitory action against SARS$\mathrm{CoV}$, the infection that causes SARS in humans ${ }^{5,6,7}$. Ritonavir is combined with lopinavir to expand its plasma half-life through the inhibition of cytochrome P450. Lopinavir has action, both in vitro ${ }^{8}$ and in an animal model $^{9}$, against Middle East respiratory syndrome coronavirus (MERS-CoV), and case reports have recommended that the blend of lopinavirritonavir with ribavirin and interferon alfa came about in virologic clearance and survival ${ }^{10-12}$. Ribavirin is a nucleoside analog with a broad-spectrum of antiviral effects. Ribavirin was also found to be less effective against COVID-19. On

\section{Corresponding Author:}

Dr. Anitha Roy, Associate Professor, Department of Pharmacology, Saveetha Dental College and Hospitals, Saveetha Institute of Medical and Technical Sciences, Saveetha University, Chennai 77, Tamil Nadu, India; Phone:+91-9840787458; Email: anitharoy@saveetha.com

ISSN: 2231-2196 (Print)

Received: 20.08 .2020
ISSN: $0975-5241$ (Online)

Revised: 18.09 .2020
Accepted: 14.10 .2020 
the other end, Remdesivir even at a very low micromolar concentration blocked the viral infection. Ribavirin combination with Lopinavir/ Ritonavir was intravenously infused for not more than 10 days. The presence or absence of viral load was determined to be the endpoint. Besides these drugs, Favipiravir is a drug that warrants attention. Favipiravir is currently undergoing clinical trials in treating COVID-19 ${ }^{13}$. Effective transmission, Severe infection, Recurrence, mortality, no specific antiviral treatment are the challenges faced. Hence, this study discusses the antiviral treatment strategies in COVID-19.

\section{COVID-19}

The initial clinical sign of the SARS-CoV-2 related disease COVID-19 with the detection of pneumonia. Recent studies describe gastrointestinal symptoms and asymptomatic infections associated with COVID-19, especially among young children. Studies have discovered that the virus can infect both mature and progenitor enterocytes, which are intestinal absorptive epithelial cells. A study conducted in China revealed that patients with COVID-19 infection had liver dysfunction at some point in their illness. Observations so far suggested that a mean incubation period of five days and a median incubation period of 3 days is required for COVID-19 (range: 0-24 days). The proportion of asymptomatic individuals infected by COVID-19 has not been assessed yet. In symptomatic patients, the clinical manifestations consist of nasal congestion, cough, sore throat, fever, fatigue, and upper respiratory tract infections. The infection later progresses to severe disease with dyspnoea and severe chest symptoms corresponding to pneumonia in approximately $75 \%$ of patients, diagnosed by computed tomography on admission ${ }^{14}$. COVID-19 makes use of the angiotensin-converting enzyme-II (ACE-2) for its entry via receptor-mediated endocytosis and it primarily affects the lung alveolar epithelial cells ${ }^{15}$.

\section{ANTIVIRAL TREATMENT STRATEGIES}

\section{Lopinavir/ Ritonavir}

Lopinavir/ritonavir is a drug combination for the human immunodeficiency virus (HIV) type 1 aspartate protease inhibitor, as this combination possesses in vitro inhibitory action against SARS-CoV, the infection that causes SARS in humans ${ }^{5}$. Ritonavir is also given in combination with lopinavir to expand plasma half-life through the inhibition of cytochrome P450. Lopinavir/ritonavir (400 mg and $100 \mathrm{mg}$, separately) to ribavirin decreases the risk of adverse clinical conditions (Acute Respiratory Distress Syndrome [ARDS] or death) as well as viral load among patients with SARS. Lopinavir has action, both in vitro ${ }^{8}$ and in an animal model
9, against Middle East respiratory syndrome coronavirus (MERS-CoV), and case reports have recommended that the blend of lopinavir-ritonavir with ribavirin and interferon alfa came about in virologic clearance and survival ${ }^{11}$. Lopinavir/Ritonavir used in combination with other medications to treat adults and children over 14 days of age infected with HIV-1.

\section{Remdesivir}

Remdesivir is another potential drug for the treatment of COVID-19. Remdesivir is a nucleoside analog and it is a broad-spectrum antiviral drug. It is also known as GS-5734 and is a mono phosphoramidite prodrug of an adenosine analog. Remdesivir has a broad antiviral spectrum including filoviruses, paramyxoviruses, pneumoviruses, and coronaviruses Remdesivir can effectively decrease the viral load in the lungs infected with MERS-CoV, and also enhances the lung function, and alleviate pathological damage to lung tissue $^{16}$. It was found that remdesivir potently blocks SARS$\mathrm{CoV}-2$ infection even at low micromolar concentrations and has a half-maximal effective concentration (EC50) of 0.77 $\mu \mathrm{M}$ and half-cytotoxic concentration (CC50) of more than $100 \mu \mathrm{M}^{17}$.

\section{Ribavirin}

Ribavirin is a nucleoside analog with a broad-spectrum of antiviral effects. Ribavirin is a guanosine analog that can interfere with the replication of RNA and DNA viruses. However, the antiviral activity of ribavirin is not limited to interference with the polymerase enzyme alone, it also interferes with RNA capping by directly inhibiting inosine monophosphate dehydrogenase. Ribavirin helps in the introduction of random mutations that reduces the viability of the virus. The mechanism of action of ribavirin helps to enhance the protective immunity ${ }^{18}$.

\section{Favipiravir}

Favipiravir was recently approved for the treatment of novel influenza on February 15, 2020, in China. This drug is currently undergoing clinical trials in treating COVID-19. Favipiravir is an RNA-dependent RNA polymerase inhibitor. In addition to its anti-influenza virus activity, favipiravir is also capable of blocking the replication of flavivirus, alphavirus, filovirus, bunyavirus, arenavirus, norovirus, and other RNA viruses. Favipiravir is converted into an active phospho ribosylated form and is recognized as a substrate by viral RNA polymerase leading to the inhibition of RNA polymerase activity. Hence, favipiravir may have potential antiviral action on COVID-19 ${ }^{19,20}$.

\section{Other Antiviral treatment strategies}

Darunavir is a second-generation HIV-1 protease inhibitor that inhibits SARS-CoV-2 infection in vitro. Cell experi- 
ments indicated that at a concentration of $300 \mu \mathrm{M}$ darunavir was able to block the viral replication in vitro ${ }^{13}$. Other potential drugs include type-II transmembrane serine protease (TMSPSS2) inhibitors and BCR-ABL kinase inhibitor imatinib. Imatinib has anti-corona activity primarily because it inhibits the fusion of virions with the endosomal membrane ${ }^{21,22}$. Studies report 30 agents with potential antiviral activity against SARS-CoV-2 which are lopinavir, ritonavir, remdesivir, darunavir, raltegravir, maribavir, deoxyrhapontin, indinavir, montelukast, disulfiram, saquinavir, fosamprenavir, polydatin, carfilzomib, atazanavir, tipranavir, shikonin, presatovir, abacavir, elvitegravir, chalcone, carmofur, enzaplatovir, tideglusib, bortezomib, PX12, TDZD-8, cyclosporin $\mathrm{A}$, and cinanserin ${ }^{23}$.

\section{CLINICAL TRIAL ON ANTIVIRAL DRUGS}

A Randomized, controlled, open-label trial having hospitalized adult patients with confirmed SARS-CoV-2 infection, that causes Covid-19, and an Oxygen saturation $\left(\mathrm{SaO}_{2}\right)$ of $94 \%$ or less while they were breathing ambient air and a ratio of the partial pressure of oxygen $\left(\mathrm{PaO}_{2}\right)$ to the fraction of inspired oxygen $\left(\mathrm{FiO}_{2}\right)$ of less than $300 \mathrm{~mm} \mathrm{Hg}$. Patients were randomly administered lopinavir-ritonavir (400 $\mathrm{mg}$ and $100 \mathrm{mg}$, respectively) twice a day for 14 days in a 1:1 ratio, and in addition to standard care, or standard care alone. And the percentages of patients with detectable viral RNA at various time points were found to be similar. Gastrointestinal adverse effects were more common in the lopinavir-ritonavir group, but serious adverse effects were more common in the standard care group. Lopinavir-ritonavir treatment was stopped early in patients with adverse effects ${ }^{24}$

A randomized, placebo-controlled, phase III clinical trial was performed in China in which the patients in the experimental group were intravenously administered an initial dose of $200 \mathrm{mg}$ of remdesivir and then $100 \mathrm{mg}$ for 9 consecutive days subsequently. Patients in the control group were administered the same dose of placebo with routine treatment. Remdesivir use is not associated with a difference in time. Patients who were administered with remdesivir had a faster time in showing clinical improvement than those receiving placebo with symptom duration of 10 days or less, adverse events including gastrointestinal symptoms (anorexia, nausea, and vomiting), aminotransferase or bilirubin increases, and worsened cardiopulmonary status ${ }^{25}$.

A study compared 111 patients with ribavirin and 41 patients treated with lopinavir/ ritonavir and ribavirin and it was found that patients treated with the combined therapy (lopinavir/ ritonavir and ribavirin) had a lower risk of developing acute respiratory distress syndrome (ARDS) ${ }^{5}$.

On February 14, the Clinical Medical Research Center of the National Infectious Diseases performed a clinical trial with favipiravir for the treatment of COVID-19 and achieved promising results. The preliminary results conducted among a total of 80 patients (including the experimental group and the control group) showed that favipiravir had more potent antiviral action than that of lopinavir/ritonavir. Favipiravir had significantly lesser adverse effects than the lopinavir/ ritonavir group ${ }^{13}$.

\section{OTHER TREATMENT MODALITIES IN COVID-19}

Novel drug delivery approaches for lung cancers ${ }^{26}$ and chronic inflammatory respiratory disease are important as the Mortality rate appears to be unexpectedly higher in patients with lung cancer and COVID-19 infection and also in patients with Chronic inflammatory respiratory disease.

\section{Anti-malarial: Hydroxychloroquine and Chloro- quine}

Hydroxychloroquine (an analog of chloroquine) has an antiSARS-CoV activity in vitro. Hydroxychloroquine clinical safety profile is better than that of chloroquine (during longterm use) and allows a higher daily dose and has fewer concerns about drug-drug interactions. Chloroquine is used to prevent and treat malaria and is efficacious as an anti-inflammatory agent for and was found to inhibit the SARS-CoV-2 infection even at a low micromolar concentration. ${ }^{27}$

\section{Anti-bacterial: Azithromycin}

Azithromycin is the drug that has been the most widely used against respiratory infections and a recent study showed that one in eight American patients, has been prescribed azithromycin in case of COVID-19. ${ }^{27}$

\section{Anti-viral: Lopinavir/Ritonavir, Remdesivir and Ribavirin}

Lopinavir/Ritonavir is an orally administrable drug, and after its administration, the viral load is being tested. On the other end, Remdesivir even at a very low micromolar concentration blocked the viral infection. Ribavirin combination with Lopinavir/ Ritonavir was intravenously infused for not more than 10 days.

\section{Ayurvedic Approach}

Studies suggest that COVID-19 in diabetic patients could result in the reduction of inflammatory cytokines release and ACE2 binding capacity for the virus, only if the patients are in good metabolic control ${ }^{28}$, which consistently might help in improving the prognosis in people affected by SARS-CoV-2 . Hence, the antihyperglycemic effect ${ }^{29}$ can be obtained with the administration of Caralluma fimbriata extract which is also known for its cytotoxic effect against cancer cells ${ }^{30}$. 
Acacia catechu possesses immunomodulatory effects $^{31}$ which can be useful in treating the COVID-19 infection. The ethanolic bark extract and seed extract can modulate the innate immune response of phagocytes especially the chemotactic migration of phagocytes, phagocytic ability, and the release of ROS(Reactive Oxygen species) ${ }^{32}$. The ethanolic bark extract and seed extract of Acacia catechu is known to cause apoptosis of Squamous cell carcinoma(SCC) cells ${ }^{33}$, especially the seed extract can trigger apoptosis against SCC -25 cells $^{34}$ Coumarin derivative, which is found to be effective against human stomach cancer cells ${ }^{35}$ is also an emerging antiviral agent against hepatitis, HIV, influenza can be considered as a future scope for treatment against COVID-19. ${ }^{36}$

Meliacin anhydride and other compounds derived from Neem (Azadirachta indica), ingesting Neem leaves extract powder or crude Neem leaves, might inhibit the COVID19 virus by preventing it from replicating. And also Neem leaves are known to reduce blood sugar levels and also they act as ACE inhibitors ${ }^{37}$. Additionally, Neem leaves have more than 140+ compounds like quercetin, zinc along with Vitamins like Vitamin C, E \& K, and ingesting them orally will also boost immunity ${ }^{38}$.

\section{Nanotechnology}

Future scope for antiviral treatment against COVID-19 also includes nanotechnology-nanoparticles and nanosensors with the use of Selenium nanoparticles ${ }^{39}$, Silver nanoparticles ${ }^{40}$, and Zinc oxide nanoparticles ${ }^{41,42,43}$ in combating against the Novel Coronavirus. The four major pathobiological aspects, including oxidative stress ${ }^{44}$, genotoxicity, inflammation ${ }^{45}$, and fibrosis ${ }^{46}$, must be considered with the context of nanoparticles and associated approaches.

\section{PREVENTION}

Hand sanitization with soap and water, and having an alcohol-based hand rub. Social distancing from anyone who is coughing or sneezing, mouth masks, personal protective suit in case of the medical profession, Self-isolation. seeking medical attention, following the directions of local health authorities ${ }^{47}$.

\section{CONCLUSION}

The antiviral drugs involved in the treatment of COVID 19 are Lopinavir/Ritonavir, Remdesivir, and Ribavirin and 30 other potential agents that are still under clinical trial. Remdesivir was found to be more effective against COVID 19 with a $30 \%$ speedy recovery. Lopinavir-ritonavir treatment was stopped early in patients because of adverse events. The most frequent severe adverse events observed were hypertransaminasemia and acute kidney injury. Remdesivir benefited patients with SARS-CoV-2 pneumonia hospitalized outside ICU where the clinical outcome was better and adverse events are less frequently observed. Ribavirin combination with Lopinavir/ Ritonavir was intravenously infused for not more than 10 days and was found to be less effective. However, prevention is always better than cure, the prevention methods involve hand sanitization, use of gloves, masks, protective suits, social distancing, and self-isolation. This review concludes with the expectation of a new vaccine for the prevention of COVID-19 at the earliest.

\section{ACKNOWLEDGEMENT}

The authors are thankful to Saveetha Dental college for providing a platform to express our knowledge and we acknowledge the immense help received from the scholars whose articles are cited and included in references to this manuscript. The authors are also grateful to authors / editors /publishers of all those articles, journals, and books from which the literature for this article has been reviewed and discussed.

\section{Conflict of Interest}

No potential conflict of interest relevant to this article was reported.

\section{Financial Support}

This research did not receive any specific grant from funding agencies in the public, commercial, or not-for-profit sectors.

\section{REFERENCES}

1. Huang C, Wang Y, Li X, Ren L, Zhao J, Hu Y, et al. Clinical features of patients infected with 2019 novel coronavirus in Wuhan, China. Lancet 2020 ; 395 (10223): 497-506.

2. Chen N, Zhou M, Dong X, Qu J, Gong F, Han Y, et al. Epidemiological and clinical characteristics of 99 cases of 2019 novel coronavirus pneumonia in Wuhan, China: a descriptive study. Lancet 2020 ; 395 (10223) : 507-13.

3. Wang D, Hu B, Hu C, Zhu F, Liu X, Zhang J, et al. Clinical Characteristics of 138 Hospitalized Patients With 2019 Novel Coronavirus-Infected Pneumonia in Wuhan, China. JAMA 2020 ; 323(11): 1061-9.

4. Liu K, Fang Y-Y, Deng Y, Liu W, Wang M-F, Ma J-P, et al. Clinical characteristics of novel coronavirus cases in tertiary hospitals in Hubei Province. Chin Med J 2020; 133 (9):1025-31.

5. Chu CM, Cheng VCC, Hung IFN, Wong MML, Chan KH, Chan KS, et al. Role of lopinavir/ritonavir in the treatment of SARS: initial virological and clinical findings. Thorax 2004; 59(3):252-6.

6. Chen F, Chan KH, Jiang Y, Kao RYT, Lu HT, Fan KW, et al. In vitro susceptibility of 10 clinical isolates of SARS coronavirus to selected antiviral compounds. J Clin Virol 2004 ; 31(1) : 69-75. 
7. Wu C-Y, Jan J-T, Ma S-H, Kuo C-J, Juan H-F, Cheng Y-SE, et al. Small molecules targeting severe acute respiratory syndrome human coronavirus. Proc Natl Acad Sci U S A $2004 ; 101$ (27):10012-7.

8. de Wilde AH, Jochmans D, Posthuma CC, Zevenhoven-Dobbe JC, van Nieuwkoop S, Bestebroer TM, et al. Screening of an FDA-approved compound library identifies four small-molecule inhibitors of Middle East respiratory syndrome coronavirus replication in cell culture. Antimicrob Agents Chemother 2014; 58 (8):4875-84.

9. Chan JF-W, Yao Y, Yeung M-L, Deng W, Bao L, Jia L, et al. Treatment With Lopinavir/Ritonavir or Interferon- $\beta 1 \mathrm{~b}$ Improves Outcome of MERS-CoV Infection in a Nonhuman Primate Model of Common Marmoset. J Infect Dis 2015; 212(12):1904-13.

10. Kim UJ, Won E-J, Kee S-J, Jung S-I, Jang H-C. Combination therapy with lopinavir/ritonavir, ribavirin and interferon- $\alpha$ for Middle East respiratory syndrome. Antivir Ther 2016; 21(5):455-9.

11. Spanakis N, Tsiodras S, Haagmans BL, Raj VS, Pontikis K, Koutsoukou A, et al. Virological and serological analysis of a recent Middle East respiratory syndrome coronavirus infection case on a triple combination antiviral regimen. Int $\mathrm{J}$ Antimicrob Agents 2014 ; 44 (6):528-32.

12. Min C-K, Cheon S, Ha N-Y, Sohn KM, Kim Y, Aigerim A, et al. Comparative and kinetic analysis of viral shedding and immunological responses in MERS patients representing a broad spectrum of disease severity. Sci Rep 2016 ; 6:25359.

13. Dong L, Hu S, Gao J. Discovering drugs to treat coronavirus disease 2019 (COVID-19). Drug Discov Ther 2020; 14(1):58-60.

14. Li Y, Xia L. Coronavirus Disease 2019 (COVID-19): Role of Chest CT in Diagnosis and Management. AJR Am J Roentgenol $2020 ; 214$ (6):1280-6.

15. Tavazzi G, Pellegrini C, Maurelli M, Belliato M, Sciutti F, Bottazzi A, et al. Myocardial localization of coronavirus in COVID-19 cardiogenic shock. Eur J Heart Fail 2020 ; 22 (5): 911-5.

16. Sheahan TP, Sims AC, Leist SR, Schäfer A, Won J, Brown AJ, et al. Comparative therapeutic efficacy of remdesivir and combination lopinavir, ritonavir, and interferon beta against MERS-CoV. Nature Communications 2020 ; 11(1):222.

17. Wang M, Cao R, Zhang L, Yang X, Liu J, Xu M, et al. Remdesivir and chloroquine effectively inhibit the recently emerged novel coronavirus (2019-nCoV) in vitro. Cell Res 2020 ; 30(3):269-71.

18. Khalili JS, Zhu H, Mak NSA, Yan Y, Zhu Y. Novel coronavirus treatment with ribavirin: Groundwork for an evaluation concerning COVID-19. J Med Virol 2020 ; 92(7) : 740-746.

19. Furuta Y, Komeno T, Nakamura T. Favipiravir (T-705), a broad spectrum inhibitor of viral RNA polymerase. Proc Jpn Acad Ser B Phys Biol Sci 2017; 93(7):449-63.

20. Delang L, Abdelnabi R, Neyts J. Favipiravir as a potential countermeasure against neglected and emerging RNA viruses. Antiviral Res $2018 ; 153: 85-94$.

21. Hoffmann M, Kleine-Weber H, Krüger N, Mueller MA. The novel coronavirus 2019 (2019-nCoV) uses the SARS-coronavirus receptor ACE2 and the cellular protease TMPRSS2 for entry into target cells. BioRxiv 2020 ; 2(15):126-28.

22. Coleman CM, Sisk JM, Mingo RM, Nelson EA, White JM, Frieman MB. Abelson Kinase Inhibitors Are Potent Inhibitors of Severe Acute Respiratory Syndrome Coronavirus and Middle East Respiratory Syndrome Coronavirus Fusion. J Virol 2016 ; 90(19):8924-33.

23. Wu W-Y et al. Current Status and Future Perspective in the Globalization Of Traditional Chinese Medicines. World Journal of Traditional Chinese Medicine 2015; 1(1):1-4.
24. Cao B, Wang Y, Wen D, Liu W, Wang J, Fan G, et al. A Trial of Lopinavir-Ritonavir in Adults Hospitalized with Severe Covid-19. N Engl J Med 2020 ; 382(19):1787-99.

25. Grein J, Ohmagari N, Shin D, Diaz G, Asperges E, Castagna A, et al. Compassionate Use of Remdesivir for Patients with Severe Covid-19. N Engl J Med 2020 ; 382(24):112-14

26. Sharma P, Mehta M, Dhanjal DS, Kaur S, Gupta G, Singh H, et al. Emerging trends in the novel drug delivery approaches for the treatment of lung cancer. Chem Biol Interact 2019;309:108720.

27. Gautret P, Lagier J-C, Parola P, Hoang VT, Meddeb L, Mailhe $\mathrm{M}$, et al. Hydroxychloroquine and azithromycin as a treatment of COVID-19: results of an open-label non-randomized clinical trial. Int J Antimicrob Agents $2020 ; 105949$.

28. Ceriello A. Hyperglycemia and the worse prognosis of COVID-19. Why a fast blood glucose control should be mandatory. Diabetes Res Clin Pract $2020 ; 163: 108186$.

29. Ashwini S, Anitha R. Antihyperglycemic Activity of Caralluma fimbriata: An In vitro Approach. Pharmacogn Mag 2017 ;13(Suppl 3):S499-504.

30. Ashwini S, Ezhilarasan D, Anitha R. Cytotoxic effect of Caralluma fimbriata against human colon cancer cells. Pharmacognosy Journal 2017; 9(2).204-07.

31. Sunil MA, Sunitha VS, Radhakrishnan EK, Jyothis M. Immunomodulatory activities of Acacia catechu, a traditional thirst quencher of South India. J Ayurveda Integr Med. $2019 ; 10$ (3):185-91.

32. Gheena S, Ezhilarasan D. Syringic acid triggers reactive oxygen species-mediated cytotoxicity in HepG2 cells. Hum Exp Toxicol 2019 ; 38(6):694-702.

33. Lakshmi T, Ezhilarasan D, Nagaich U, Vijayaragavan R. Acacia catechu Ethanolic Seed Extract Triggers Apoptosis of SCC-25 Cells. Pharmacogn Mag 2017 ; 13 (Suppl 3):S405-11.

34. Lakshmi T, Ezhilarasan D, Vijayaragavan R, Bhullar SK, Rajendran R. Acacia catechu ethanolic bark extract induces apoptosis in human oral squamous carcinoma cells. J Adv Pharm Technol Res. 2017 ; 8(4) :143-9.

35. Perumalsamy H, Sankarapandian K, Veerappan K, Natarajan S, Kandaswamy N, Thangavelu L, et al. In silico and in vitro analysis of coumarin derivative induced anticancer effects by undergoing intrinsic pathway mediated apoptosis in human stomach cancer. Phytomedicine $2018 ; 46: 119-30$.

36. Mishra S, Pandey A, Manvati S. Coumarin: An emerging antiviral agent. Heliyon $2020 ; 6(1): \mathrm{e} 03217$.

37. Subramanian S. Some Neem Leaves extract compounds exhibit very high binding affinity against COVID-19 Main Protease (Mpro): A Molecular Docking Study. Journal of Cluster Science $2020 ; 6(3): 216-33$.

38. Lakshmi T, Krishnan V, Rajendran R, Madhusudhanan N. Azadirachta indica: A herbal panacea in dentistry - An update. Pharmacogn Rev 2015 ;9(17):41-4.

39. Menon S, Ks SD, Santhiya R, Rajeshkumar S, S VK. Selenium nanoparticles: A potent chemotherapeutic agent and an elucidation of its mechanism. Colloids and Surfaces B: Biointerfaces $2018 ; 170: 280-292$.

40. Karthiga P, Rajeshkumar S, Annadurai G. Mechanism of Larvicidal Activity of Antimicrobial Silver Nanoparticles Synthesized Using Garcinia mangostana Bark Extract. Journal of Cluster Science 2018 ; 29(6):1233-41.

41. Rajeshkumar S, Kumar SV, Ramaiah A, Agarwal H, Lakshmi T, Roopan SM. Biosynthesis of zinc oxide nanoparticles using Mangifera indica leaves and evaluation of their antioxidant and cytotoxic properties in lung cancer (A549) cells. Enzyme Microb Technol 2018 ;117: 91-5. 
42. Rajeshkumar S. Synthesis of Zinc oxide nanoparticles using algal formulation (Padina tetrastromatica and Turbinaria conoides) and their antibacterial activity against fish pathogens. Res J Biotechnol 2018; 13(9) : 15-9.

43. Rajeshkumar S, Agarwal H, Kumar SV, Lakshmi T. Brassica oleracea mediated synthesis of zinc oxide nanoparticles and its antibacterial activity against pathogenic bacteria. Asian J Chem 2018; 30 (12):2711-5.

44. Ezhilarasan D. Oxidative stress is bane in chronic liver diseases: Clinical and experimental perspective. Arab J Gastroenterol $2018 ; 19$ (2):56-64.
45. Mehta M, Deeksha, Tewari D, Gupta G, Awasthi R, Singh H, et al. Oligonucleotide therapy: An emerging focus area for drug delivery in chronic inflammatory respiratory diseases. Chem Biol Interact. 2019 ; 308:206-15.

46. Ezhilarasan D, Sokal E, Najimi M. Hepatic fibrosis: It is time to go with hepatic stellate cell-specific therapeutic targets. Hepatobiliary Pancreat Dis Int $2018 ; 17$ (3):192-7.

47. Miglani S, Ansari MI, Ahuja B, Gupta A. Use of Newer Protective and Disinfection Strategies: A Simple Tool Guide for the Dentists During the COVID-19 Pandemic .Int J Cur Res and Rev $2020 ; 12$ (16):151-4. 